\section{TUMOURS OF THE CEREBELLUM.}

\section{To the Editor of THE LANCET.}

SIR, - A yaper by Dr. Stephen Mackenzie on the Diagnosis of Tumours of the Cerebellum, which has just appeared in your columns, contains, besides much which is useful and interesting, so many statements which are at variance with the conclusions hitherto arrived at with regard to this subjeet, that I cannot allow them to pass unchallenged. There is still so much confusion in our knowledge of intracranial tumours that a rigid criticism of the cases brought forward, and the opinions based thereon, seems imperatively required, and this must be my excuse for the following observations :-

I would say, then, that to my thinking not one of the three cases on which Dr. Mackenzie's paper is based can be utilised for the diagnosis of tumours of the cerebellum, since two of them are incomplete, and in the third extensive lesions existed at the same time in other structures.

In the first case, which is described as one of myxomatous glioma of the cerebellum, neither the pons and medulla, nor the spinal cord appear to have been examined; yet this should have been done, seeing that the symptoms which were present during life point strongly to disease in those parts. The retraction of the head and the tetanic seizures, which led Dr. Mackenzie to diagnose without hesitation tumour of the cerebellum, I should have referred to an irritative lesion of the medulla or the upper portion of the cord. Tumour of the cerebellum alone never causes either of the symptoms mentioned by Dr. Mackenzie as appertain ing to it. In order to prove this assertion, I could mention a considerable number of well-observed cases, but will content myself with referring to those recorded by Ebstein " Osteoma of the Cerebellum," in Virchow's Archiv, vol. xlix., p. 145), by Ferber ("Glio-sarcoma," in " Beiträge zur Symptomatologie," \&c., Marburg, 1875), and by Bull ("Sarcoma," in Philadelphia Med. Times, May 15th, 1875).

The second of Dr. Mackenzie's cases, which is described as one of "solitary tubercle," is not one of disease localised in the cerebellum ; for from his own description of the postmortem changes, it appears that there was likewise a large tubercular mass in the left lateral ventricle, "projecting into it from about the situation of the corpus striatum." The condition of the pons is not mentioned, but the medulla was " so much flattened as to be almost riband-like." This case cannot therefore teach us anything about tumours of the cerebellum, as it clashes with the first principle of localisation in cerebral disease - viz., that the lesion from the occurrence of which diagnostic conclusions are to be drawn must be limited in extent, and not affect important neighbouring structures, either by pressure or otherwise.

In the third case, which was likewise one of tubercle, the condition of the pons, medulla, and cord does not appear to have been examined; only the " nerves of the medulla " are stated to have been healthy. Tubercle, however, is apt to be diffused, and may be suspected in the pons and medulla where convulsive or epileptiform seizures have taken place during life. Interesting as Dr. Mackenzie's cases, no doubt, are, as examples of intracranial tumours, they must, for the reasons I have just given, be looked upon as quite unsuited for serving as guides for the diagnosis of cerebellar disease.

I now proceed to notice the clinical remarks in Dr. Mackenzie's paper, and cannot help expressing my surprise that he should not have laid more stress upon the circum. stance that tumour of the cerebellum may exist without causing any symptoms at all. Yet this is one of the best attested facts in cerebral localisation. Indeed, a whole cerebellar hemisphere may be diseased, and yet there may not be a single morbid sign to draw attention to such a condition. Symptoms appear to occur only when the middle lobe is affected, while disease in the lateral lobes is often impossible to recognise on this account.

Amongst the chief symptoms of cerebellar tumour, Dr. lackenzie mentions :-

1. The reeling gait; and this constitutes unquestionably the most important sign of the disease. I cannot, however, agree with him in saying that it differs entirely from the walk in locomotor ataxy. The walk in the two affections is generally very similar, and in some cases it is impossible to draw a distinction. In connexion with this it is important to know that cerebellar ataxy is almost invariably confined to the legs and the body, and does not affect the movements of the arms and hands, even in cases where the legs are so unsteady that the patient cannot make a single step without falling. Such a state of things is exceptional in posterior spinal sclerosis, and therefore furnishes valuable indications.

2. Tonic convulsions are, according to Dr. Mackenzie, of the greatest importance as distinctive of cerebellar disease ; indeed, he sees the strongest reason for believing that tetanus is an affection of the cerebellum! This statement I must absolutely contradict. On analysing the cases in which tumours occurred in the cerebellum only, it is found that any form of motor irritation, whether it be tremor, clonic or tonic convulsion, did either not occur at all, or that, if it existed, it could be traced to more or less severe pressure by the tumour on the pons and medulla. In direct opposition to Dr. Mackenzie, I therefore maintain that tonic convulsions and other signs of motor irritation speak against rather than for disease localised in the cerebellum.

3. Dr. Mackenzie states that movements of the eyeballs are frequently connected with cerebellar tumours ; but cases recorded by other observers show that such movements do not occur in disease of the cerebellum itself, but only in irritative lesions of the crura cerebelli ad pontem.

4. Enlargement of the head, which Dr. Mackenzie considers a sign of the greatest value for cerebellar tumours, appears to me to be quite devoid of importance. It does not occur in adults who are subject to such tumours, and is seen in children in a variety of other intracranial diseases. It therefore cannot teach us anything at all definite about the cerebellum.

Singularly enough, one of the commonest symptoms of cerebellar tumour, and one which ranks in importance next to the reeling gait, has been quite overlooked by Dr. Mackenzie : I mean a peculiar form of vertigo. It is distin. guished from vertigo dependent upon other cerebral lesions by being extremely severe, and sometimes permanent; and that it is not the consequence of the cerebellar ataxy, is shown by the fact that it occurs in some cases before a reeling gait is noticed, and also while the patient is in the recumbent position. It is, however, always more marked when he sits up in bed or attempts to walk. It gets worse on closing the eyes, and better by supporting the patient. The sensation experienced is either one as if all external things were moving and spinning round, or as if the body itself were constantly on the move. As vertigo occurs likewise in disease of the semicircular canals, a stomacho læso, \&c., it is on that account no reliable sign of a cerebellar tumour if present alone; but when it is observed simultaneously with cerebellar ataxy, it becomes of the utmost importance, more especially as it is characteristic of tumour, and does not occur with atrophy, hæmorrhage, softening, and other diseases of the cerebellum. All other symptoms which are sometimes ascribed to cerebellar tumour, such as vomiting, occipital headache, optic neuritis, \&c., are unreliable; the only safe guides for our diagnosis of these cases being cerebellar ataxy and cerebellar vertigo.

$$
\text { I am, Sir, your obedient servant, }
$$
Julius Althaus, M.D.

Bryanston-street, Marble-arch, April 17th, 1880.

\section{MR. BADCOCK'S EXPERIMENTS ON THE VARIOLISATION OF KINE. \\ To the Editor of THE LANCE'T.}

SIR, - While admitting the general cogency of $\mathrm{Mr}$. Richardson's letter on this subject, I can only regard his allusions to the analogy of the vegetable world as showing his failure to apprehend the grave difficulties presented to the biologist by the facts with which he deals. It would, no doubt, be surprising if, by a careful selection of soil, we succeeded in producing cucumber from radish, but not so the raising of a plant differing as widely from radish as a case of vaccinia from one of small-pox. With our new plant, however, we might safely predict the reappearance of the parent features on reverting to the original conditions of production; and that Mr. Badcock's vaccine lymph should behave otherwise is one of those facts which seem to stand isolated and incredible to all but eye-witnesses until analogies have been discovered linking them with the world of personal experience. "The fact is," as Mr. Richardson remarks, "vaccine is a disease sui generis," and, being so, I fail to see that the history of its derivation from small-pox 